\title{
Self-incompatibility in ryegrass. X. Number and frequency of alleles in a natural population of Lolium perenne L.
}

\author{
C. H. FEARON, M. A. CORNISH, M. D. HAYWARD $\dagger$ \& M. J. LAWRENCE* \\ Wolfson Laboratory for Plant Molecular Biology, School of Biological Sciences, University of Birmingham, Birmingham \\ B15 $2 T T$ and tInstitute of Grassland and Environmental Research, Plas Gogerddan, Aberystwyth SY23 3EB, U.K.
}

\begin{abstract}
A crossing procedure to extract one $S$ - and one $Z$-allele, at random, from each of a number of plants of Lolium perenne, to examine the number and frequency of incompatibility alleles they contain is described. This procedure has been used on a random sample of plants from the longestablished population of perennial ryegrass in North Meadow, Cricklade. In all, 17 different $S$ alleles and 17 different $Z$-alleles were found in a sample of 38 and 39 plants, respectively. The frequencies of these alleles were very unequal, one of the $S$-alleles occurring 12 times and two of the $Z$-alleles nine times each. The $E_{2}$ estimator of O'Donnell \& Lawrence (1984) gave estimates of 31 alleles at each locus, although these estimates are probably less than the actual number of $S$ - and $Z$-alleles in this population. Analysis of the theoretical properties of the two-locus polymorphism, suggests that, with this number of alleles, the strength of the frequency-dependent selection that maintains the polymorphism must be weak, that a population will contain only a subset of the total number of genotypes and that the unequal allele frequencies might be caused by either or both of these effects.
\end{abstract}

Keywords: Lolium perenne, population genetics, self-incompatibility.

\section{Introduction}

Although several investigations of the number and frequency of incompatibility alleles in populations of species with a one-locus gametophytic system of selfincompatibility have been carried out (Emerson, 1939; Atwood, 1944; Williams \& Williams, 1947; Campbell \& Lawrence, 1981a,b; Lawrence \& O'Donnell, 1981), there has been only one on a species with a two-locus gametophytic system. Lundqvist (1962, 1964, 1969) found $11 \mathrm{~S}$ - and $12 \mathrm{Z}$-alleles in the Festuca pratensis cultivar, 'Svalof Late'. As this cultivar was derived from the self-pollinated progeny of a single plant, however, general conclusions about the properties of the selfincompatibility polymorphism in populations of grasses are limited. This paper presents the results from an assay of the number and frequency of incompatibility alleles in a very long-established natural population of Lolium perenne.

\section{Analytical procedure}

The number and frequency of incompatibility alleles in a sample of plants drawn at random from a population of a species with a one-locus gametophytic system of self-incompatibility can be determined directly from data obtained by crossing each plant in the sample with every other to give a half-diallel set of pollinations. In these circumstances, crosses between plants that have no $S$-alleles in common are fully compatible, those between plants that have one $S$-allele in common are half-compatible and those between plants that have both alleles in common are incompatible.

The problem with species that possess a two-locus gametophytic system of self-incompatibility is that only those crosses between plants that have alleles in common at both loci give less than full compatibility. Hence, it is not possible to determine the incompatibility genotypes of a sample of unrelated plants of a species with a two-locus system directly; to accomplish this objective, it is necessary to make two or three rounds of preliminary crosses between each of the 
plants of the sample and those of known incompatibility genotype which serve as testers.

The crossing scheme used in the present investigation is a development of the procedure used by Lundqvist (Table 1). A factorial set of genotypes which are double homozygotes for the incompatibility loci is used to sample, at random, one $S$ - and one $Z$-allele from each of the individuals of a sample and to produce two complementary sets of progeny, in one of which plants differ only in respect of the $S$-alleles that have been sampled (the $S$-diallel set) and in the other plants differ only in respect of the $Z$-alleles that have been sampled from the population (the $Z$-diallel set).

Table 1 The crossing scheme used to extract one $S$ - and one $Z$-allele from each of the plants of a sample to be analysed for the number and frequency of incompatibility alleles they contain

Stage 1. Each of a sample of plants taken at random from the population to be assayed is crossed to a tester of genotype $S_{1.1} Z_{1.1}$ :

$$
\begin{aligned}
& S_{\text {a.b }} Z_{\text {c.d }} \times S_{1.1} Z_{1.1} \\
& \downarrow \\
& S_{\mathrm{a} .1} Z_{\mathrm{c} .1} \quad S_{\mathrm{a} .1} Z_{\mathrm{d} .1} \quad S_{\mathrm{b} .1} Z_{\mathrm{c} .1} \quad S_{\mathrm{b} .1} Z_{\mathrm{d} .1}
\end{aligned}
$$

Stage 2. One of the plants raised from the seed of each of the stage 1 crosses is crossed to a second tester whose genotype, $S_{2.2} Z_{2.2}$, is complementary to that of the first tester:

$$
\begin{aligned}
& S_{\text {a.l }} Z_{\text {c. } 1} \times S_{2.2} Z_{2.2} \\
& \downarrow \\
& S_{\text {a. } 2} Z_{\text {c. } 2} \quad S_{\text {a. } 2} Z_{1.2} \quad S_{1.2} Z_{\text {c. } 2} \quad S_{1.2} Z_{1.2}
\end{aligned}
$$

\begin{tabular}{|c|c|c|c|}
\hline \multirow[b]{2}{*}{ Females } & \multicolumn{2}{|c|}{ Pollen from } & \multirow[b]{2}{*}{ Decision } \\
\hline & $S_{1.1} Z_{2.2}$ & $S_{2.2} Z_{1.1}$ & \\
\hline$S_{\mathrm{a} .2} Z_{\mathrm{c} .2}$ & + & + & $\rightarrow$ discard \\
\hline$S_{\mathrm{a} .2} Z_{1.2}$ & + & - & $\rightarrow S$-diallel \\
\hline$S_{1.2} Z_{\mathrm{c} .2}$ & - & + & $\rightarrow Z$-diallel \\
\hline$S_{1.2} Z_{1.2}^{c .2}$ & - & - & $\rightarrow$ discard \\
\hline \multicolumn{4}{|c|}{+ , fully compatible; - , incompatible. } \\
\hline \multicolumn{4}{|c|}{$\begin{array}{l}\text { Stage 4. Each of the plants of the } S \text {-diallel set is pollinated } \\
\text { with every other in the set and similarly for those of the } Z \text { - } \\
\text { diallel set }\end{array}$} \\
\hline
\end{tabular}

Stage 3. The genotypes of each of, say, 10 plants raised from the seed of each of the stage 2 crosses can be determined by using pollen from the remaining pair of the factorial set of testers, $S_{1.1} Z_{2.2}$ and $S_{2.2} Z_{1.1}$, as follows:
The number of plants from the population that are crossed to the $S_{1.1} Z_{1.1}$ tester at stage 1 of the scheme determines the final size of the two sets of diallels as each of the former contributes one descendant to each of the latter. Because all pollinations between the plants of each diallel set (stage 4) are either half-compatible or incompatible, the task of classifying these pollinations is easier than when all four kinds of pollination are expected.

It is possible to extract both $S$ - and both $Z$-alleles from each of these plants if one plant of each of the four genotypes that are expected to occur in the progeny of each stage 1 cross is carried foward to stage 2 , rather than choosing a single plant at random, as in Table 1 . To be 95 per cent certain of obtaining at least one plant of each of these four classes, it would be necessary to raise not less than 16 plants in each progeny (Lawrence et al., 1978). Plants could then be assigned to one or other of these four classes by interpollinating them, the expected pattern of pollinations being shown in Table 2 . Each of the plants sampled from the population to be assayed would then contribute two plants to the $S$-diallel set and two to the $Z$ diallel set of stage 4 , so that it would be possible to deduce their full incompatibility genotype. This modification is, however, considerably more demanding than the scheme shown in Table 1 and could be contemplated only when the sample of plants to be completely assayed was quite small. We have used the unmodified scheme in the present investigation.

Compared with Lundqvist's crossing procedure, the present one requires an extra round of preliminary crosses and four double homozygotes rather than three. These homozygotes, however, do not have to be obtained from the population to be investigated, nor is it necessary to discard any of the plants in the sample because of their allelic constitution. The present scheme, therefore, is both more general and more efficient than that proposed by Lundqvist.

Table 2 Pattern of pollinations expected when crosses are made between plants raised from the seed of a stage 1 cross

\begin{tabular}{lcccc}
\hline & \multicolumn{4}{c}{ Males } \\
\cline { 2 - 5 } Females & $S_{\text {a. } 1} Z_{\mathrm{c} .1}$ & $S_{\mathrm{a} .1} Z_{\mathrm{d} .1}$ & $S_{\mathrm{b} .1} Z_{\mathrm{c} .1}$ & $S_{\mathrm{b} .1} Z_{\mathrm{d} .1}$ \\
\hline$S_{\mathrm{a} .1} Z_{\mathrm{c} .1}$ & - & $\mathrm{H}$ & $\mathrm{H}$ & $\mathrm{T}$ \\
$S_{\mathrm{a} .1} Z_{\mathrm{d} .1}$ & $\mathrm{H}$ & - & $\mathrm{T}$ & $\mathrm{H}$ \\
$S_{\mathrm{b} .1} Z_{\mathrm{c} .1}$ & $\mathrm{H}$ & $\mathrm{T}$ & - & $\mathrm{H}$ \\
$S_{\mathrm{b} .1} Z_{\mathrm{d} .1}$ & $\mathrm{~T}$ & $\mathrm{H}$ & $\mathrm{H}$ & - \\
\hline
\end{tabular}

$\mathrm{H}$, half-compatible; $\mathrm{T}$, three-quarters compatible. 


\section{Materials and methods}

\section{Double homozygotes}

The double homozygotes were obtained by the enforced self-pollination of selected plants from Family $F$ of Cornish et al. (1979). The genotypes of the four double homozygotes derived in this way were $S_{1.1} Z_{1.1}$, $S_{2.2} Z_{1.1}, S_{2.2} Z_{1.1}$ and $S_{2.2} Z_{2.2}$, the first being obtained independently from three different selfed progenies, the second from two and the remainder from the same progeny. Thereafter, these homozygotes were maintained and multiplied by clonal replication. Although these homozygotes were obtained by one or more rounds of enforced self-pollination and exhibited some inbreeding depression, they were very nearly as selfincompatible as their noninbred ancestors.

\section{Source population}

The sample of perennial ryegrass plants was obtained from North Meadow, Cricklade (O.S. map reference: SU 0994), a very long-established (800 years), large (40 ha), alluvial, botanically-rich hay meadow, which has been traditionally managed for a very long time (Ratcliffe, 1977). A total of 104 plants were collected by sampling at intervals of $4.7 \mathrm{~m}$ along a transect. Although $L$. perenne is not a dominant species in the dense sward of this meadow, no difficulty was experienced in finding one or more tillers of it within $30 \mathrm{~cm}$ of each sampling point. The plants from which $S$ - and $Z$-alleles were extracted for the present investigation were sampled at random from this collection.

\section{Maintenance and multiplication of material and crossing and pollination procedures}

To ensure that the tillers collected originated from different genotypes, a single tiller was taken from each clump and transplanted into a seed tray containing John Innes Potting Compost No. 1 and grown on until they had reached a size where they could be transferred to $15 \mathrm{~cm}$ plastic pots placed outdoors. The homozygous testers were multiplied by clonal propagation to provide enough plants for the crossing scheme shown in Table 1.

Plants for crossing or pollination were brought into the glasshouse in January and induced to flower early under supplementary lighting set to give a day length of $16 \mathrm{~h}$. Crosses were made by Jenkin's (1931) automatic cross-pollination without emasculation method and diagnostic pollinations by Lundqvist's (1961) in vitro method.

With a species, such as L. perenne, whose individuals reproduce vegetatively, there is a risk that tillers taken from adjacent sampling stations along a transect are clonal replicates of the same genotype. This possibility was investigated by determining the enzyme phenotype of the individuals of each sample with respect to six polymorphic loci, $P G I-2, G O T-2, G O T$ 3, $P G M-1, A P-1$ and $A P-2$ (Hayward \& McAdam, $1977 \mathrm{a}, \mathrm{b})$. Only one pair of plants originating from tillers taken from adjacent sampling stations had the same multiple phenotype in each sample, which suggests that clonal spread is unlikely to be very great in this population; these plants were excluded from the sample taken for the present investigation.

The crossing programme was initiated by crossing each of 66 plants drawn at random from the collection to the $S_{1.1} Z_{1.1}$ tester. On completion, 38 plants were analysed in the $S$-diallel and 39 in the $Z$-diallel, 35 of the latter being descended from the same North Meadow ancestors as the former. The sizes of these diallels were determined by the numbers of plants that could be handled in the time available at stages 3 and 4 of the programme. All plants were scored for their $P G I-2$ and $A P-2$ phenotype to check for contamination by pollen or seed.

\section{Results}

Seventeen alleles were found at each locus (Tables 3 and 4 ), the frequencies of which were very unequal. Thus, while 12 of the $S$-alleles occurred only once, one

Table 3 Partial incompatibility genotype of the 42 plants classified in the $S$ - and $Z$-diallels

\begin{tabular}{|c|c|c|c|c|c|}
\hline \multirow[b]{2}{*}{ Plant no. } & \multicolumn{2}{|c|}{ Genotype } & \multirow[b]{2}{*}{ Plant no. } & \multicolumn{2}{|c|}{ Genotype } \\
\hline & $S_{\mathrm{a}}$ & $Z_{\mathrm{c}}$ & & $S_{\mathrm{a}}$ & $Z_{\mathrm{c}}$ \\
\hline 3 & 1 & 1 & 47 & 12 & 15 \\
\hline 5 & 6 & 3 & 49 & 5 & 5 \\
\hline 6 & 3 & 4 & 52 & 13 & 2 \\
\hline 8 & 7 & 6 & 56 & 1 & 2 \\
\hline 13 & 2 & 4 & 58 & 4 & 16 \\
\hline 14 & - & 7 & 59 & 14 & 1 \\
\hline 18 & 8 & 8 & 60 & 5 & 2 \\
\hline 23 & 1 & 1 & 61 & 2 & 1 \\
\hline 24 & 9 & 9 & 62 & 1 & 2 \\
\hline 25 & - & 10 & 64 & 4 & 2 \\
\hline 26 & 3 & 11 & 65 & 15 & - \\
\hline 27 & 4 & 2 & 66 & 2 & 1 \\
\hline 29 & 2 & 12 & 72 & 1 & 1 \\
\hline 30 & - & 13 & 76 & 3 & 3 \\
\hline 31 & 1 & 3 & 77 & 1 & 5 \\
\hline 33 & 1 & 2 & 78 & 1 & 17 \\
\hline 34 & 2 & 1 & 79 & 1 & 2 \\
\hline 35 & 10 & 14 & 87 & 16 & - \\
\hline 37 & 11 & 2 & 88 & 2 & 3 \\
\hline 42 & - & 1 & 95 & 1 & 3 \\
\hline 45 & 1 & - & 101 & 17 & 1 \\
\hline
\end{tabular}


Table 4 Summary of the data in Table 3. Repeatability, a measure of the thoroughness with which an assay of the number and frequency of alleles has been carried out (Campbell \& Lawrence, 1981a), is calculated here as $R=(r-n) /(r-2)$, where $r=$ number of alleles $(=$ number of plants) and $n=$ number of different alleles found, to allow for the fact that the polymorphism can be maintained with as few as two alleles per locus. The $\chi^{2}$-test of the hypothesis that the alleles are equally frequent in the population from which these samples have been drawn is a modified version of that given by Campbell \& Lawrence (1981b) because only one allele has been sampled from each locus of the North Meadow plants, rather than both, so that in this case:

$\chi_{(n-1)}^{2}=(n-1) \frac{\left(\sum_{j=1}^{n} C_{j}^{2}-\frac{r^{2}}{n}\right)}{\left(r-\frac{r}{n}\right)}=\frac{n}{r}\left(\sum_{j=1}^{n} C_{j}^{2}-\frac{r^{2}}{n}\right)$ (a) $S$-alleles

No. of plants sampled $=38$

No. of alleles found $=17$

Repeatability $=0.58$

Frequency distribution of these alleles:

$\begin{array}{lrlllllllllll}\text { No. of occurrences } & 1 & 2 & 3 & 4 & 5 & 6 & 7 & 8 & 9 & 10 & 11 & 12\end{array}$ $\begin{array}{lllllllllllll}\text { No. of alleles } & 12 & 1 & 2 & 0 & 0 & 1 & 0 & 0 & 0 & 0 & 0 & 1\end{array}$

$P\left(\chi_{16}^{2} \geq 57.737\right)=0.000003$

(b) Z-alleles

No. of plants sampled $=39$

No. of alleles found $=17$

Repeatability $=0.59$

Frequency distribution of these alleles:

No. of occurrences $\quad \begin{array}{lllllllll}1 & 2 & 3 & 4 & 5 & 6 & 7 & 8 & 9\end{array}$

$\begin{array}{llllllllll}\text { No. of alleles } & 12 & 2 & 0 & 0 & 1 & 0 & 0 & 0 & 2\end{array}$

$P\left(\chi_{16}^{2} \geq 51.231\right)=0.000026$

occurred 12 times in the sample of $38 S$-alleles examined (Table 4a). Similarly, while 12 of the $Z$ alleles also occurred only once, two occurred nine times in the sample of $39 \mathrm{Z}$-alleles (Table $4 \mathrm{~b}$ ).

These data can be used to estimate the number of alleles in the population from which this sample of plants was drawn. As the allele frequencies are significantly unequal at both loci, the most appropriate expression for this purpose is the $E_{2}$ estimator of O'Donnell \& Lawrence (1984), which gives an estimate of 31 alleles at each locus.

Lastly, as the repeatibility, $R$, for $S$-alleles is 0.58 and that for the $Z$-alleles is 0.59 (Campbell \& Lawrence, 1981a), this assay of the number and frequency of incompatibility alleles is nearly as thorough as those carried out on species with a onelocus system of incompatibility by Emerson (1939) with Oenothera organensis and by Campbell \& Lawrence (1981b) and Lawrence and O'Donnell (1981) with Papaver rhoeas (see also Lawrence et al., 1993).

\section{Discussion}

\section{Some theoretical considerations}

Before discussing these results, the first from any natural population of a species with a two-locus gametophytic system of self-incompatibility, it is necessary to consider the properties of this polymorphism. In general, these properties are similar to those of the one-locus gametophytic polymorphism (Wright, 1939; Campbell \& Lawrence, 1981a). Thus, because this polymorphism is also maintained by gene-frequencydependent selection, the number of alleles at each locus is potentially very large and, provided that the effect of selection is limited to that associated with incompatibility, the equilibrium frequency of each of the alleles is, allowing for drift, expected to be approximately $1 / k_{1}$ and $1 / k_{2}$ for a population that contains $k_{1}$ $S$-alleles and $k_{2} Z$-alleles, respectively. Again, while the selective advantage of an allele is negatively related to its frequency in the population, the magnitude of this advantage is also negatively related to the number of alleles present.

There are, however, three differences between the properties of the two-locus and those of the one-locus polymorphism. First, whereas the minimum number of alleles required to maintain the one-locus polymorphism is three, that for the two-locus case is two at each locus because whereas individuals cannot be homozygous at both loci, they may be at one or the other. Secondly, with $k_{1} S$-alleles and $k_{2} Z$-alleles in a population, the total number of genotypes is $k_{1} k_{2}\left(k_{1} k_{2}-1\right) /$ 2 , if 'coupling' and 'repulsion' double heterozygotes are distinguished, of which $k_{1} k_{2}\left(k_{1}+k_{2}-2\right)$ are single and $k_{1} k_{2}\left(k_{1}-1\right)\left(k_{2}-1\right) / 2$ are double heterozygotes (Lundqvist, 1962). If $k_{1}=k_{2}=k$, the total number of genotypes is $k^{2}\left(k^{2}-1\right) / 2$, the number of single heterozygotes is $k^{2}(k-1)$ and the number of double heterozygotes is $k^{2}(k-1)^{2} / 2$ (Charlesworth, 1979). If, however, the distinction between 'coupling' and 'repulsion' heterozygotes is relaxed, the total number of genotypes becomes $k^{2}(k-1)(k+3) / 4$. As the total number of genotypes, when $k$ alleles are present in a population of a species with a one-locus system, is $k(k-1) / 2$, the ratio of the number of genotypes expected with a two-locus system to that expected with a one-locus system is $k(k+3) / 2$; i.e. the two-locus 
polymorphism is, for a given $k$, much more extensive than the one-locus polymorphism. For example, if $k=31$, the total number of genotypes expected in a population is 465 for a one-locus system but no less than 245055 for the two-locus case. Hence, unless $k$ is very small, a population can be expected to contain only a subset of the total number of genotypes.

The third difference concerns the negative relationship between the selective advantage of an allele, that appears in the population by mutation or migration, and the number of alleles already present. Lawrence et al. (1994) pointed out that the strength of the frequency-dependent selection that maintains the one-locus polymorphism becomes considerably attenuated as the number of alleles in the population increases. This attenuation is much more striking in the case of the two-locus polymorphism. In order to investigate this effect, we need to calculate the proportion of crosses between a pair of plants drawn at random from a population that are incompatible; this proportion can be found as follows. Suppose that the first plant drawn is a single heterozygote of genotype $S_{1.1} Z_{1.2}$. Then this plant will be incompatible as a female only with another plant of the same genotype. But the number of different single heterozygotes in a population containing $k S$ - and $k Z$-alleles is, from the previous paragraph, $k^{2}(k-1)$. Hence, the number of incompatible crosses between single heterozygotes is also equal to $k^{2}(k-1)$. Consider, now, double heterozygotes. Suppose the first plant drawn is of genotype $S_{1.2} Z_{1.2}$. Then this plant will be incompatible as a female with another plant of the same genotype, as well as with the four single heterozygotes, $S_{1.1} Z_{1.2}, S_{2.2} Z_{1.2}$, $S_{1.2} Z_{1.1}$ and $S_{1.2} Z_{2.2}$; i.e. with six different genotypes if we continue to recognize the difference between 'coupling' and 'repulsion' heterozygotes. As the number of different double heterozygotes in the population is $k^{2}(k-1)^{2} / 2$, the number of incompatible crosses involving double heterozygotes as females is, therefore:

$\left[k^{2}(k-1)^{2} / 2\right] \times 6=3 k^{2}(k-1)^{2}$.

Hence, the total number of incompatible crosses expected in a population containing $k$ alleles at each locus is:

$k^{2}(k-1)+3 k^{2}(k-1)^{2}=k^{2}(k-1)(3 k-2)$.

The number of pairwise combinations between genotypes in a population containing a total of $k^{2}\left(k^{2}-1\right) / 2$ different genotypes is, including reciprocals and selfs, the square of this number. Thus, assuming that, at equilibrium, the frequency of single heterozygotes is the same as that of double heterozygotes, the expected proportion of incompatible crosses between pairs of plants chosen at random is:

$$
\begin{aligned}
& {\left[k^{2}(k-1)(3 k-2)\right] /\left[k^{2}\left(k^{2}-1\right) / 2\right]^{2}=[4(3 k-2)] /} \\
& \quad\left[k^{2}(k-1)(k+1)^{2}\right] .
\end{aligned}
$$

Charlesworth's (1979) calculations show that at equilibrium, provided $k$ is not very small, the frequencies of individual single homozygotes are very similar to those of individual double heterozygotes (assuming that coupling and repulsion kinds of the latter are distinguished) and that both are close to the reciprocal of the total number of genotypes; the assumption that all genotypes are equally frequent, therefore, can be justified (but see below). The expected percentage cross-incompatibility in populations containing from two to 20 equally frequent alleles at each locus is shown in Table 5. Although these results are the same as those obtained by Lundqvist (1963), he showed the relationship between the number of alleles and percentage cross-incompatibility in graphical form only, without also giving the expression on which this relationship is based.

Before turning to consider the implications of the results shown in this table, it is worth calculating, also,

Table 5 Percentage cross-incompatibility between zygotes and pollen incompatibility for different numbers $(k)$ of equally frequent genotypes and alleles for (a) one-locus and (b) two-locus systems of self-incompatibility. For the onelocus case, the proportion of randomly chosen pairs of plants which are expected to be incompatible is $2 /[k(k-1)]$ and the proportion of stigmas on which a pollen grain of genotype $S_{\mathrm{i}}$ is expected to be incompatible is $2 / k$ (Lawrence et al., 1994). See text for the comparable expressions for the two-locus

\begin{tabular}{|c|c|c|c|c|}
\hline \multirow[b]{2}{*}{$k$} & \multicolumn{2}{|c|}{$\begin{array}{l}\text { Cross-incompatibility } \\
(\%)\end{array}$} & \multicolumn{2}{|c|}{$\begin{array}{l}\text { Pollen incompatibiliity } \\
\qquad(\%)\end{array}$} \\
\hline & (a) & (b) & (a) & (b) \\
\hline 2 & - & 44.44 & - & 66.67 \\
\hline 3 & 33.33 & 9.72 & 66.67 & 33.33 \\
\hline 4 & 16.67 & 3.33 & 50.00 & 20.00 \\
\hline 5 & 10.00 & 1.44 & 40.00 & 13.33 \\
\hline 6 & 6.67 & 0.73 & 33.33 & 9.52 \\
\hline 7 & 4.76 & 0.40 & 28.57 & 7.14 \\
\hline 8 & 3.57 & 0.24 & 25.00 & 5.56 \\
\hline 9 & 2.78 & 0.15 & 22.22 & 4.44 \\
\hline 10 & 2.22 & 0.10 & 20.00 & 3.64 \\
\hline 12 & 1.52 & 0.05 & 16.17 & 2.56 \\
\hline 14 & 1.10 & 0.03 & 14.29 & 1.90 \\
\hline 15 & 0.95 & 0.02 & 13.33 & 1.67 \\
\hline 16 & 0.83 & 0.02 & 12.50 & 1.47 \\
\hline 18 & 0.65 & 0.01 & 11.11 & 1.17 \\
\hline 20 & 0.53 & 0.01 & 10.00 & 0.95 \\
\hline
\end{tabular}
case 
the probability that a pollen grain carrying a particular $S-Z$ pair of alleles alights at random on the stigma of a plant containing the same pair. Suppose the genotype of the pollen grain is $S_{1} Z_{1}$. Considering, first, single homozygotes, $(k-1)$ of those that are homozygous for $S_{1}$ will also contain $Z_{1}$; similarly, $(k-1)$ of those that are homozygous for $Z_{1}$ will also contain $S_{1}$. The number of single homozygotes that contain both $S_{1}$ and $Z_{1}$ is, thus, $2(k-1)$. By a similar argument, the number of double heterozygotes that contain $S_{1}$ and $Z_{1}$ in the 'coupling' phase is $(k-1)^{2}$, so that, in all, the number of double heterozygotes that are expected to contain both of these alleles is $2(k-1)^{2}$. Hence, the total number of genotypes in the population on whose stigmas an $S_{1} Z_{1}$ pollen grain is incompatible is $2(k-1)+2(k-1)^{2}=2 k(k-1)$. Then the proportion of genotypes which have this property is $2 k(k-1) /$ $\left[k^{2}\left(k^{2}-1\right) / 2\right]=4 /[k(k+1)]$. The expected percentage pollen incompatibility in populations containing from two to 20 equally frequent alleles at each locus is shown in Table 5 , which also shows the percentage cross and pollen incompatibilities for the one-locus case for comparison.

The results shown in this table leave no doubt that the rate of reduction of both cross-incompatibility and pollen incompatibility, as the number of alleles in the population rises, is much higher in a two-locus than in a single-locus system. Thus, whereas 15 equally frequent alleles are required before cross-incompatibility in the population falls below 1 per cent in the one-locus case, only six alleles are required to achieve the same level of cross-incompatibility with two loci. Again, while 48 alleles are required to reduce cross-incompatibility to 0.1 per cent with one locus, only 10 are required with two loci. However, although the rate of reduction of pollen incompatibility is much higher with two loci than with one, both are appreciably lower than their respective rates of reduction of cross-incompatibility. For example, while 200 alleles are required before pollen incompatibility falls to 1 per cent with one locus, only 20 are required to give the same level of pollen incompatibility with two loci.

Now, because incompatibility between zygotes and pollen is the force which drives the frequency-dependent selection that maintains these polymorphisms, these calculations suggest that the strength of this selection becomes rapidly attenuated as the number of alleles in the population rises. Once a population contains more than, say, $20 S$ - and $Z$-alleles, this selection must become quite weak, so that drift may have a more important effect on allele frequencies than selection in populations at equilibrium containing more than this number of alleles. These calculations are not, of course, intended to do more than illustrate this pheno- menon; a proper mathematical analysis of the problem would be welcome.

\section{Number of S- and Z- alleles in the North Meadow population}

Two points are worth making about the number of alleles in this population. Firstly, our estimate of 31 alleles at each locus is almost certainly an underestimate. Thus, while the $E_{2}$ estimator, devised for samples from three natural populations of Papaver rhoeas, in which allele frequencies were significantly unequal, yielded estimates that were less biased than those from the maximum likelihood procedure (Paxman, 1963), they were still biased downwards (O'Donnell \& Lawrence, 1984). As the allele frequencies in the North Meadow sample are more unequal than in any of those of $P$. rhoeas, our estimates of 31 alleles at each locus are almost certainly even more biased, so that this ryegrass population probably contains 40 or more alleles.

Secondly, while this number of alleles is higher than expected on the argument advanced in the previous section, this assumed that allele and genotype frequencies in the population were equal, which is not the case in the North Meadow population. Although the number of unequally frequent $S$ - and $Z$-alleles required to give a particular level of cross or pollen incompatibility must be greater than when their frequencies are equal, this is an aspect of the polymorphism which, hitherto, has not been investigated. The other assumption made with the calculations of the previous section was that the population behaved as a panmictic unit. The North Meadow population, however, may be subdivided into a number of neighbourhoods because the dispersal of both pollen and seed is limited; a population of this structure could contain more alleles than one which is strictly panmictic, a possibility that could be investigated by computer simulation. Lastly, assuming that Wright's (1939) analysis of the size of a population required to maintain a given number of alleles at equilibrium is as applicable to the two-locus as it is to the one-locus case, the North Meadow population would have to have an effective size of at least 5000 to maintain 40 alleles at each locus at equilibrium. As the area of this meadow is 40 ha, the size of the ryegrass population is likely to be very large, so that even if the effective size of the population is much smaller than its census size, this is almost certainly more than large enough to maintain the number of alleles that it is estimated to contain. 


\section{The frequency of the alleles in the North Meadow population}

The observation that the frequencies of the alleles are unequal at both loci is not expected from the theory advanced earlier. Campbell \& Lawrence (1981b) proposed two hypotheses to account for the unequal allele frequencies that they and Lawrence \& O'Donnell (1981) observed in their poppy populations. Firstly, that some of the alleles were subject to an extra effect of selection, over and above that involved with incompatibility, arising either from a pleiotropic property of these alleles or their linkage to another gene that is the chief target of this extra effect of selection. Secondly, that the unequal allele frequencies are caused by a sampling effect, in addition to that caused by drift, of a kind to be expected in a species occurring in disturbed habitats. As a result of a review of the relevant genetical and ecological evidence, Lawrence et al. (1994) concluded that opportunities for sampling effects to perturb allele frequencies to the extent observed was likely to be limited because the size of these populations was larger than the minimum required to maintain the number of alleles they appeared to contain and that the observation of significantly disturbed segregation ratios in full-sib families suggested that some of the $S$-alleles in these populations were subject to an extra effect of selection as a result of their linkage to other genes (Lawrence \& Franklin-Tong, 1994).

The second hypothesis appears to be even less probable than with the poppy populations for two reasons. Firstly, the size of the North Meadow population is almost certainly much larger than those of $P$. rhoeas. Secondly, while sampling effects, in addition to drift, could be important during the first year of a newly-sown pasture of ryegrass, such opportunities appear to be limited in a stable, species-rich meadow that has been managed in the same way for many centuries. It is not unreasonable to suppose, therefore, that this population of ryegrass is in a state of equilibrium, which is why this population was chosen for investigation. In view of our previous calculation, however, that the number of genotypes in a population containing 31 alleles at each locus is no less than 245055 , it is doubtful whether the effective size of the North Meadow population is large enough to contain this number of genotypes. How likely is it, then, that the allele frequencies are equal in a population containing a subset of genotypes? This is a question that could be usefully investigated by simulating the polymorphism on the computer.

Although the first hypothesis may appear, by default, to be the more likely, we have no direct evidence that an extra effect of selection acting on the incompatibility loci is the cause of unequal allele frequencies in the North Meadow population. While disturbed segregation ratios are observed quite frequently in full-sib families of $P$. rhoeas (Lawrence \& Franklin-Tong, 1994), Cornish et al. (1979) found only two cases of disturbed segregation in the seven families of $L$. perenne they examined and Fearon et al. (1983) found only one in four families of $L$. multiflorum. The parents of these families, however, differed in one important respect from those of the North Meadow diallels in that, with one exception (Family $\mathrm{P}$ of Cornish et al.), all came from material that was regularly maintained by seed. In these circumstances, any linkage disequilibrium between the incompatibility loci and other genes that are the chief target of any extra effect of selection would be expected to decay rapidly. While the parents of the North Meadow diallels might appear to be similar as they originated from a traditional haymeadow in which individuals flower and set seed every year, the extreme density of the very species-rich sward in this meadow suggests that seedling establishment must be difficult and, hence, uncommon. If this is the case, effective sexual reproduction would also be infrequent so that any linkage disequilibrium between the incompatibility loci and other genes would, per annum, decay very slowly. The advantage of this hypothesis is that it is testable. Thus, if the unequal allele frequencies in the North Meadow population are caused by the linkage of the incompatibility loci to other genes that are the chief target of an extra effect of selection, this should cause disturbed segregation ratios with respect to the alleles of the $\bar{S}$ - and $Z$-loci in such families.

There is one further, indirect piece of evidence that suggests that the incompatibility loci in Lolium might be subject to an extra effect of selection. Thorogood \& Hayward (1992), who found that self-compatibility in L. temulentum is determined by a gene closely linked to $Z$ or by a $Z_{\mathrm{F}}$ allele, also found that this species possesses an $S$-allele which, when transfered to $L$. perenne, was as fully functional as the native $S$-alleles of the latter, despite being sheltered from the natural selection associated with incompatibility for hundreds of generations. This finding can be explained only on the assumption that this $S$-allele has pleiotropic properties, only one of which involves incompatibility. There is no reason to suppose that such effects are peculiar to the $S$-allele extracted from $L$. temulentum. Hence, while we have, hitherto, supposed that any extra effect of selection acting on the incompatibility loci results from their linkage to other genes that are the chief target of this selection, we ought to retain the possibility that this selection could result from a pleiotropic property of at least some of the alleles at these loci. 


\section{Acknowledgements}

The work described in this paper was supported initially by an SERC CASE studentship to C.H.F. and latterly by an AFRC Research Grant to M.J.L. both of which are gratefully ackowledged. We also wish to acknowledge Neil McAdam, a member of staff at IGER, Aberystwyth, and the horticultural staff in Birmingham without whose skilled and devoted assistance this work could not have been carried out.

\section{References}

ATwood, s. s. 1944. Oppositional alleles in natural populations of Trifolium repens. Genetics, 29, 428-435.

CAMPBELL, J. M. AND LAWRENCE, M. J. 1981a. The population genetics of the self-incompatibility polymorphism in Papaver rhoeas. I. The number and distribution of $S$ alleles in families from three localities. Heredity, 46, 69-79.

CAMPBELL, J. M. AND LAWRENCE, M. J. 1981b. The population genetics of the self-incompatibility polymorphism in Papaver rhoeas. II. The number and frequency of $S$-alleles in a natural population (R106). Heredity, 46, 81-90.

CHARLESWORTH, D. 1979. Some properties of populations with multilocus homomorphic gametophytic incompatibility systems. Heredity, 43, 19-25.

CORNISH, M. A., HAYWARD, M. D. AND LAWRENCE, M. J. 1979. Selfincompatibility in ryegrass. I. Genetic control in diploid Lolium perenne L. Heredity, 43, 95-106.

EMERSON, s. 1939. A preliminary survey of the Oenothera organensis population. Genetics, 24, 524-537.

FEARON, C. H., HAYWARD, M. D. AND LAWRENCE, M. J. 1983. Selfincompatibility in ryegrass. V. Genetic control, linkage and seed-set in diploid Lolium multiflorum Lam. Heredity, 50, 35-45.

HAYWARD, M. D. AND McADAM, N. J. 1977a. Isozyme polymorphism as a measure of distinctiveness and stability in cultivars of Lolium perenne. Z. Pflanzenzuchtg., 79, 59-68.

HAYWARD, M. D. AND McADAM, N. J. 1977b. Genetic control of isozyme phenotypes in L. perenne. Rep. Welsh Pl. Br. Stn for 1976, pp. 28-29.

JENKIN, T. J. 1931. The breeding of herbage plants. Methods and techniques of selection, breeding and strain building in grasses. Bull. Bur. Pl. Genet. Aberystwyth, 3, 1-34.

LAWRENCE, M. J., AFZAL, M. AND KENRICK, J. 1978. The genetical control of self-incompatibility in Papaver rhoeas. Heredity, 40, 239-253.

LAWRENCE, M. J. AND FRANKLIN-TONG, V. E. 1994. The population genetics of the self-incompatibility polymorphism in Papaver rhoeas. IX. Evidence of an extra effect of selection acting on the $S$-locus. Heredity, 72, 353-364.
LAWRENCE, M. J., LANE, M. D., O'DONNELL, S. AND FRANKLIN-TONG, V. E. 1993. The population genetics of the self-incompatibility polymorphism in Papaver rhoeas. V. The cross-classification of the $S$-alleles from samples from three natural populations. Heredity, 71, 581-590.

LAWRENCE, M. J. AND O'DONNELL, s. 1981. The population genetics of the self-incompatibility polymorphism in Papaver rhoeas. III. The number and frequency of $S$ alleles in two further natural populations (R102 and R104). Heredity, 47, 53-61.

LAWRENCE, M. J., O'DONNELL, S., LANE, M. D. AND MARSHALL, D. F. 1994. The population genetics of the self-incompatibility polymorphism in Papaver rhoeas. VIII. Sampling effects as a possible cause of unequal allele frequencies. Heredity, 72, 345-352.

LUNDQVIST, A. 1961. A rapid method for the analysis of incompatibility in grasses. Hereditas, 47, 705-707.

LUNDQVIST, A. 1962. The nature of the two-loci incompatibility system in grasses. II. Number of alleles at the incompatibility loci in Festuca pratensis Huds. Hereditas, 48 , 169-181.

LUNDQVIST, A. 1963. Self-incompatibility and the breeding of herbage grasses. In: Åkerberg, E. and Hagberg, A. (eds) Recent Plant Breeding Research, pp. 193-202. Almqvist and Wiksell, Stockholm.

LUNDQVIST, A. 1964. The nature of the two-loci incompatibility system in grasses. III. Frequency of specific alleles in a population of Festuca pratensis Huds. Hereditas, 52, 189-195.

LUNDQVIST, A. 1969. The identification of the self-incompatibility alleles in a grass population. Hereditas, 61, $345-352$.

o'DONNELL, S. AND LAWRENCE, M.J. 1984. The population genetics of the self-incompatibility polymorphism in Papaver rhoeas. IV. The estimation of the number of alleles in a population. Heredity, 53, 495-507.

PAXMAN, G.J. 1963. The maximum likelihood estimation of the number of self-sterility alleles in a population. Genetics, 48, 1029-1032.

RATCLIFFE, D. (ED.). 1977. A Nature Conservation Review, Vol. 2, p.128. Cambridge University Press, Cambridge.

THOROGOOD, D. AND HAYWARD, M. D. 1992. Self-compatibility in Lolium temulentum L.; its genetic control and transfer into Lolium perenne L. and L. multiflorum Lam. Heredity, 68, 71-78.

WILLIAMS, R .D. AND WILLIAMS, w. 1947. Genetics of red clover (Trifolium pratense L.) compatibility. III. The frequency of incompatibility alleles in two non-pedigree populations of red clover. J. Genet., 48, 67-79.

WRIGHT, s. 1939. The distribution of self-sterility alleles in populations. Genetics, 24, 538-552. 